\title{
THERMAL EFFECT AND FREQUENCY RESPONSE ANALYSES ON HETEROJUNCTION BIPOLAR POWER TRANSISTOR
}

\author{
K. F. YARN ${ }^{\mathrm{a}, *}$ and K. H. HO ${ }^{\mathrm{b}}$ \\ ${ }^{a}$ Optoelectronic Semiconductor Center, Department of Electrical Engineering, \\ Far East College, Hsin-Shih, Tainan, Taiwan 744, Republic of China; ${ }^{\mathrm{b}}$ Institute \\ of Microelectronics, Department of Electrical Engineering, National Cheng- \\ Kung University, Tainan, Taiwan 701, Republic of China
}

(Received 25 June 2001; In final form 20 August 2001)

\begin{abstract}
Heterojunction bipolar transistors (HBT) based on $\mathrm{Npn}$ AlGaAs/GaAs material system have attracted considerable attention for microwave power and digital applications due to their high speed and high current capabilities. In this paper, a numerical model based on the Npn AlGaAs/GaAs HBT structure for the carrier transport is presented. Three figures of merit on device operation, current gain, cut-off frequency and maximum oscillation frequency are calculated. Besides, thermal instability plays an important role on power HBT resulted from the low thermal conductivity in GaAs. The generated heat will increase the junction temperature and cause self-destruction. Therefore, the thermal runaway study of the junction temperature, current-voltage (IV) characteristics and frequency response using an analytical thermal model is described.
\end{abstract}

\section{INTRODUCTION}

The heterojunction wide-gap emitter provides a large barrier to hinder hole current in HBT and so allows the base region to be heavily doped [1], and therefore lower the base resistance without sacrificing the

\footnotetext{
*Corresponding author. Present address: P.O. BOX 345, Tainan, Taiwan 704,
} Republic of China 
emitter injection efficiency. The low base resistance obviously results in a substantially improved frequency response. The other advantages are high current, high power gain and high efficiency $[2,3]$. But, the microwave power devices operated at such a high power level together with the poor thermal conductivity in GaAs, generate a large amount of heat and result in much higher temperature in HBT. Since some physical parameters are strongly influenced by the junction temperature, the device performance operated in power application will be significantly affected.

There are three thermal effects that cause power HBT to malfunction. The first is the temperature-dependent current gain. The current gain decreases monotonically with ambient temperature which is higher than the room temperature. The second thermal effect is secondary breakdown, a well-known phenomenon in Si bipolar transistor under high power operation. It occurs when the device temperature reaches a semiconductor intrinsic temperature at which the electrical properties are dominated by the thermal induced intrinsic carriers. Since the intrinsic temperature of $\mathrm{AlGaAs} / \mathrm{GaAs}$ is high, the secondary breakdown may not be a thermal problem. The third one is the thermal run-away. It usually occurs at a temperature lower than the other two, and it is the primary problem for limiting the power performance.

In this work, an analytical model based on the HBT model for carrier transport and frequency performance is derived in section 2 . Meanwhile, thermal instability constitutes a major reason for sudden failure in power HBTs. The nature of this phenomenon is that of a tendency for hot spots to bloom because of a positive feedback between temperature and locally increased current. The positive feedback is that local high temperature causes the lowering of base bandgap, which results in a low turn-on voltage thus inducing more current and more local heat. For iso-thermal condition, the DC current density is usually inaccurate, since the power HBT operated at high current density significantly large temperature gradients commonly exist across semiconductor devices. In section 3, the temperature dependent physical parameters are studied and calculated including thermal term. Finally, the calculated results are shown and discussed in section 4 . 


\section{THERMIONIC DIFFUSION MODEL}

The discontinuity in the conduction band edge at the emitter-base interface, as shown in Figure 1, gives rise to a barrier which impedes the injection of electrons into the base region, thus increase the current gain. Lauterbach et al. (1992) considered a thermionic diffusion model with a more realistic description of several important factors to determine the HBT operation, such as recombination current, emitter series resistance, etc. [4]. We follow this method to investigate electron transport across pn heterojunction in this section and take thermal effect into account in the next section. In addition, a unified model of the cut-off frequency $\left(f_{T}\right)$ and maximum frequency $\left(f_{\max }\right)$ is also developed.

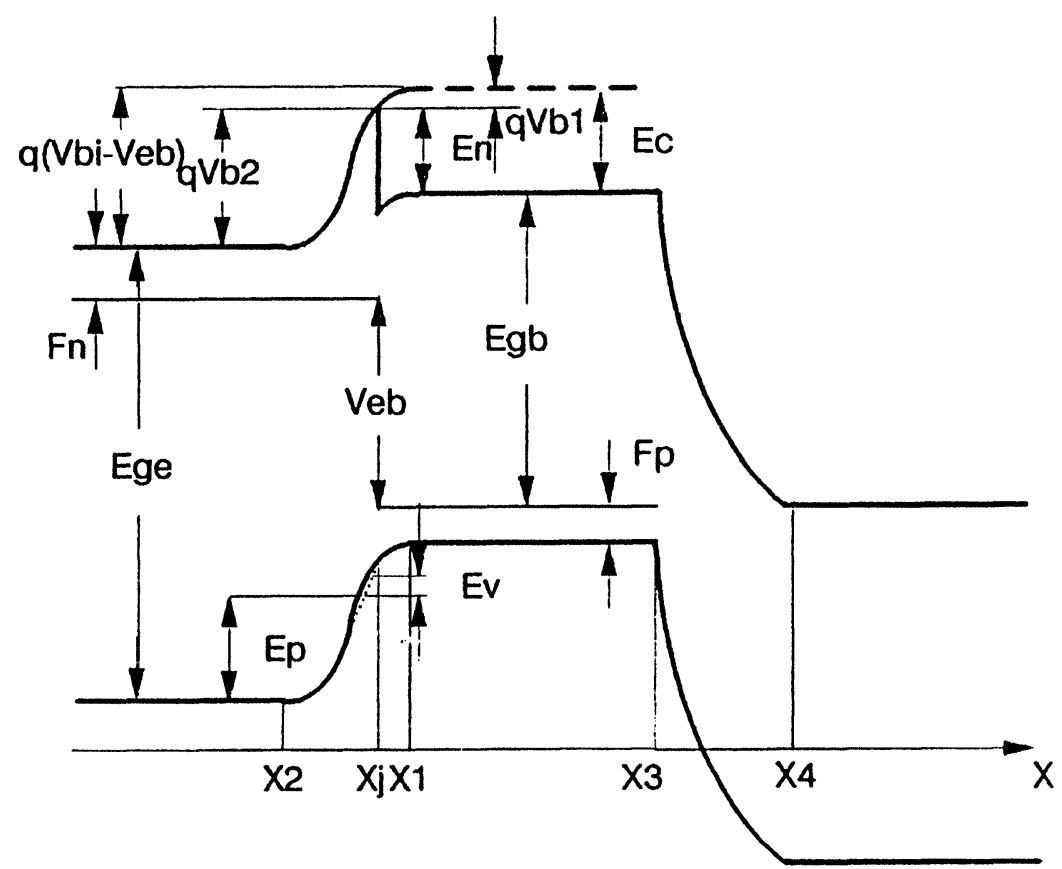

FIGURE 1 Schematic HBT band structure and device parameters. 


\subsection{Electrical Properties of HBT Model}

The electrical $I V$ model is rewritten in a form similar to Ebers-Moll equations for an HBT as follows

$$
\begin{aligned}
& J_{E}=\left(A_{11}+J_{\mathrm{rb} 1}\right)\left[\exp \left(\frac{V_{\mathrm{BE}}}{V_{t}}\right)-1\right]+\left(A_{12}+J_{\mathrm{rb} 2}\right)\left[\exp \left(\frac{-V_{\mathrm{CB}}}{V_{t}}\right)-1\right] \\
& J_{C}=A_{21}\left[\exp \left(\frac{V_{\mathrm{BE}}}{V_{t}}\right)-1\right]+A_{22}\left[\exp \left(\frac{-V_{\mathrm{CB}}}{V_{t}}\right)-1\right]
\end{aligned}
$$

where

$$
\begin{aligned}
A_{11}= & -\left[\left(\frac{J_{\mathrm{nE}}}{R_{n}}\right) \cosh \left(\frac{W_{B}}{L_{\mathrm{nB}}}\right)-\left(\frac{J_{\mathrm{pE}}}{R_{p}}\right) \cos h\left(\frac{W_{E}}{L_{\mathrm{pE}}}\right)\right] \\
A_{22}= & \left(\frac{J_{\mathrm{nE}}}{R_{n}}\right)\left[\cosh \left(\frac{W_{B}}{L_{\mathrm{nB}}}\right)+v_{n} \sinh ^{2}\left(\frac{W_{B}}{L_{\mathrm{nB}}}\right) \exp \left(\frac{-\Delta E_{n}}{k T}\right)\right. \\
& \left.+J_{\mathrm{pC}} \cosh \left(\frac{W_{C}}{L_{\mathrm{pC}}}\right)\right] \\
A_{12}= & -A_{21}=\frac{J_{\mathrm{nE}}}{R_{n}}
\end{aligned}
$$

Here, in order to achieve a more realistic HBT model, we have considered some current contributions in the device that are caused by recombination of minority carriers in the neutral base $\left(J_{\mathrm{rb} 1}\right)$, and recombination in the emitter-base space charge region $\left(J_{\mathrm{rb} 2}\right)$, where

$$
\begin{aligned}
& J_{\mathrm{rbl}}=\frac{q\left(W_{B}-X_{2}\right) n_{\mathrm{ib}}^{2}}{\left(2 \tau_{n_{2}} P_{B} R_{n}\right)} \\
& J_{\mathrm{rb} 2}=J_{\mathrm{rbl} 1}\left[R_{n}+N_{E} \exp \left(\frac{\Delta E_{n}}{V_{t}}\right)\right]
\end{aligned}
$$

Physical constants and device parameters used in the calculation are listed in Table 1. The other relevant parameters used in this paper are, $v_{p}=1.42 \times 10^{7} \mathrm{~cm} / \mathrm{sec}, v_{n}=4.16 \times 10^{7} \mathrm{~cm} / \mathrm{sec}, v_{s}=1.04 \times 10^{9}$ $\mathrm{cm} / \mathrm{sec}, \quad V_{t}=0.0259 \mathrm{~V}, \quad \Delta E_{C}=0.243 \mathrm{eV}, \quad \varepsilon_{1}=1.08 \times 10^{12} \mathrm{~F} / \mathrm{cm}$, $\varepsilon_{2}=1.16 \times 10^{12} \mathrm{~F} / \mathrm{cm}$ and $V_{\mathrm{bi}}=1.718 \mathrm{~V}$. These values are chosen to simulate an actual device. 
TABLE I Physical Constants and Parameters Used in the Calculation.

\begin{tabular}{|c|c|}
\hline $\begin{array}{l}\text { Energy band gap (eV) } \\
E_{\mathrm{ge}} / E_{\mathrm{gb}}\end{array}$ & $\begin{array}{c}1.735 / 1.424 \\
\mathrm{Al} \text { composition }=0.25\end{array}$ \\
\hline $\begin{array}{l}\text { Electron diffusion constant } \\
D_{\text {nb }}\left(\mathrm{cm}^{2} / \mathrm{s}\right)\end{array}$ & 50.33 \\
\hline $\begin{array}{l}\text { Hole diffusion constant } \\
D_{\mathrm{pe}} / D_{\mathrm{pc}}\left(\mathrm{cm}^{2} / \mathrm{s}\right)\end{array}$ & $9.0 / 10.0$ \\
\hline $\begin{array}{l}\text { Electron diffusion length } \\
L_{\mathrm{nb}}(\mu \mathrm{m})\end{array}$ & 5 \\
\hline $\begin{array}{l}\text { Hole diffusion length } \\
L_{\mathrm{pe}} / L_{\mathrm{pc}}(\mu \mathrm{m})\end{array}$ & $2.0 / 2.0$ \\
\hline $\begin{array}{l}\text { Doping concentration } \\
N_{e} / P_{b} / N_{c}\left(\mathrm{~cm}^{3}\right)\end{array}$ & $510^{17} / 110^{19} / 510^{16}$ \\
\hline $\begin{array}{l}\text { Neutral thickness } \\
\mathrm{W}_{e} / \mathrm{W}_{b} / \mathrm{W}_{c}()\end{array}$ & $1500 / 1000 / 4000$ \\
\hline
\end{tabular}

\subsection{Consideration of Frequency Response in HBT}

The frequency at which incremental current gain drops to unity is called the current gain cut-off frequency $f_{T}$, which is inversely proportional to the signal delay time $\tau_{\mathrm{EC}}$ (carrier transit time) from the emitter to the collector. It can be estimated through the relation [5]

$$
1 /\left(2 \pi f_{T}\right)=\tau_{\mathrm{EC}}=\tau_{e}+\tau_{\mathrm{eb}}+\tau_{\mathrm{bt}}+\tau_{\mathrm{ct}}+\tau_{c}
$$

where $\tau_{e}$ is the emitter region delay time, which is the emitter diffusion capacitance $\left(C_{\mathrm{dE}}\right)$ charging time through the emitter diffusion and series resistance; $\tau_{\mathrm{eb}}$ is the base-emitter plus base-collector depletion layer capacitance charging time through the emitter diffusion and series resistance; $\tau_{\mathrm{bt}}$ is the base transit time; $\tau_{\mathrm{ct}}$ is the base-collector depletion layer transit time; and $\tau_{c}$ is the base-collector depletion layer capacitance charging time through collector resistance. The delay time in emitter region is

$$
\tau_{e}=r_{e} C_{\mathrm{dE}} \sim\left(\frac{W_{E}^{2}}{2 D_{\mathrm{pE}}}\right)\left(\frac{J_{p}}{J_{n}}\right)
$$


The emitter charge time $\tau_{\mathrm{eb}}$ is the base-emitter $\left(C_{\mathrm{je}}\right)$ plus base-collector $\left(C_{\mathrm{jc}}\right)$ depletion layer capacitance charging time through the emitter diffusion and series resistance.

$$
\tau_{\mathrm{eb}}=r_{e}\left(C_{\mathrm{je}}+C_{\mathrm{jc}}\right)
$$

$C_{\mathrm{je}}$ and $C_{\mathrm{jc}}$ can be expressed as the conventional depletion capacitance model [6].

$$
\begin{aligned}
& C_{\mathrm{je}}=\left\{\frac{q N_{E} N_{B} \varepsilon}{\left[2\left(N_{E}+N_{B}\right)\left(V_{\mathrm{bi}(\mathrm{BE})}-V_{\mathrm{BE}}\right)\right.}\right\}^{0.5} \\
& C_{\mathrm{jc}}=\left\{\frac{q N_{B} N_{C} \varepsilon}{\left[2\left(N_{B}+N_{C}\right)\left(V_{\mathrm{bi}(\mathrm{BC})}+V_{\mathrm{CB}}\right)\right]}\right\}^{0.5}
\end{aligned}
$$

where $V_{\mathrm{bi}(\mathrm{BE})}$ and $V_{\mathrm{bi}(\mathrm{BC})}$ are the base-emitter and base-collector built-in voltages, respectively.

The effective base transit time is given by the ratio of the quasi neutral base thickness to the electron velocity in the base.

$$
\tau_{\mathrm{bt}}=\frac{W_{B}}{v_{\mathrm{nB}}}
$$

The quasi neutral base thickness depends on collector current. $v_{\mathrm{nB}}$ is the minority carrier electron velocity in the base.

$$
v_{\mathrm{nB}}=\frac{2 D_{n}}{W_{B}}
$$

The collector depletion layer transit time $\tau_{\mathrm{ct}}$ can be expressed as

$$
\tau_{\mathrm{ct}}=\frac{X_{3}}{\gamma v_{s}}
$$

where $X_{3}\left(=\varepsilon / C_{\mathrm{jc}}\right)$ is the collector depletion layer and $v_{s}\left(=2 \times 10^{6}\right.$ $\mathrm{cm} / \mathrm{sec})$ is the GaAs saturation drift velocity. And $\gamma$ changes from 2 in 
the absence of velocity overshoot to about 3 if velocity overshoot in the base-collector junction becomes significant [7]. Finally, the collector charge time is the product of the collector resistance and capacitance.

$$
\tau_{c}=R_{c} C_{\mathrm{jc}}
$$

The collector resistance is given by

$$
R_{c}=R_{\mathrm{cs}}+R_{\mathrm{cc}}
$$

where $R_{\mathrm{cs}}$ and $R_{\mathrm{cc}}$ are the collector series and contact resistance, respectively.

$$
r_{\mathrm{cs}}=\frac{W_{c}}{\left[q\left(D_{n} / V_{t}\right) N_{c}\right]}
$$

In addition, the cut-off frequency $f_{T}$ and the maximum frequency $f_{\max }$ are another important parameters given by [8]

$$
f_{\max }=\frac{1}{\left[8 \pi\left(R_{B} C_{\mathrm{jc}}\right)_{\mathrm{eff}} / f_{T}\right]^{0.5}}
$$

where $\left(R_{B} C_{\mathrm{jc}}\right)_{\mathrm{eff}}=C_{\mathrm{jc}}\left(R_{C}+R_{B}\right)$. The effective base resistance $R_{B}$ related to the device geometry and device parameters is an important factor in determining the frequency performance [9]. A generic layout of power HBT is shown in Figure 2 as well as the emitter-base area and mesa structure in Figure 3. The base resistance can be divided into four parts. The first part is the resistance of the base metallization. The base metallization resistance may be approximated by

$$
R_{\mathrm{bm}}=\frac{l \rho_{m}}{3 x_{b}}
$$

where $x_{b}$ is the width of the base metallization finger, $l$ is the length of base contact, and $\rho_{m}$ is the metal sheet resistance. The second component of the base resistance is the intrinsic base resistance, i.e., the resistance experienced by the base lateral current to the underneath emitter. Considering an HBT with a long, thin emitter stripe, and base contacts on both 


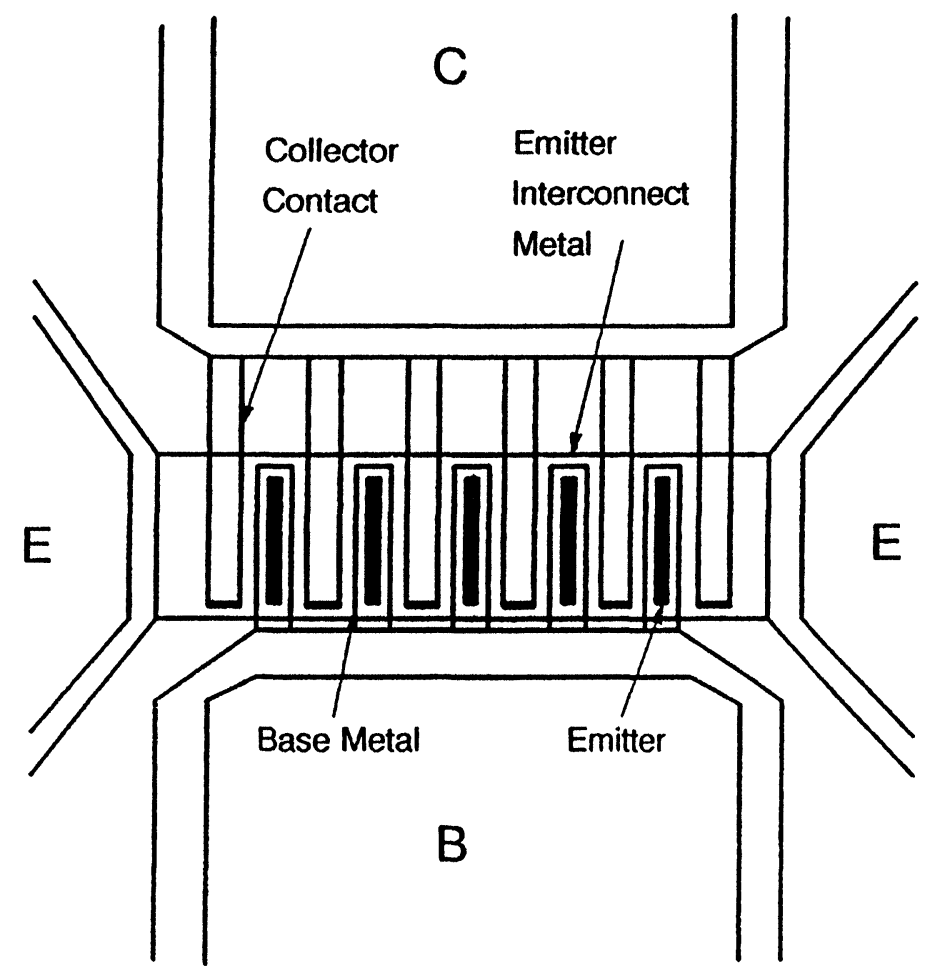

FIGURE 2 A generic layout for power and microwave HBT.

sides of the emitter, the intrinsic base resistance may be found to be equal to [10]

$$
R_{\mathrm{bint}}=\frac{\rho_{\mathrm{bsh}} x_{e}}{12 l_{e}}
$$

where $\rho_{\mathrm{bsh}}$ is the sheet resistance of the base layer $\left(=\rho_{b} / w_{b}\right)$, and $x_{e}$ and $l_{e}$ are the emitter width and length, respectively. $\rho_{b}$ is the resistivity and $w_{b}$ is the base neutral thickness in the base. The third component of the base resistance is the extrinsic base resistance, which is the resistance encountered by the current as it flow from the base contact to the portion of the base under the emitter given by

$$
R_{\mathrm{ext}}=\frac{\rho_{\mathrm{bsh}} w_{\mathrm{ext}}}{2 l_{e}}
$$



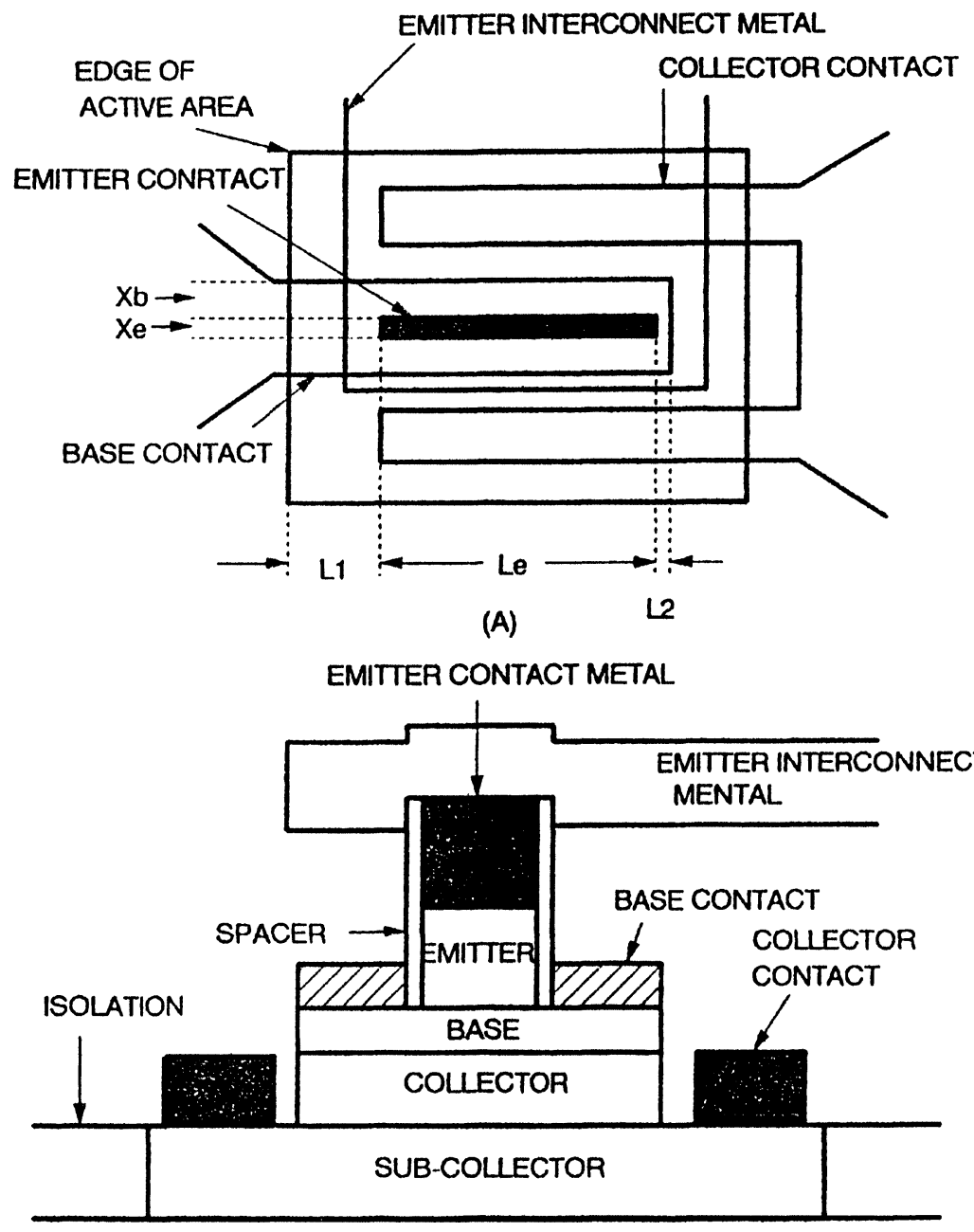

S.I. SUBSTRATE

(B)

FIGURE 3 An enlarged self-aligned HBT layout and cross-section shows the different components for RF operation. 
where $w_{\text {ext }}$ is the distance from the edge of the base contact to the edge of the emitter. The fourth component of the base resistance is the base contact resistance given by

$$
R_{c}=\left[\frac{\left(\rho_{\mathrm{bsh}} \rho_{c}\right)^{0.5}}{\left(2 l_{e}\right)}\right] \cot h\left[w\left(\frac{\rho_{\mathrm{bsh}}}{\rho_{c}}\right)^{0.5}\right]
$$

where $\rho_{c}$ is the specific contact resistivity of the base contact. The total base resistance is

$$
R_{b}=R_{\mathrm{bm}}+R_{\mathrm{bint}}+R_{\mathrm{ext}}+R_{c}
$$

if $R_{b}$ and $C_{\mathrm{jc}}$ are all reduced, then $f_{\max }$ should be enhanced.

\section{MODIFIED MODEL WITH THERMAL EFFECT}

To study the behavior and capabilities of AlGaAs/GaAs power HBTs in terms of thermal performance, the physical-based thermionic diffusion model is adequate. Indeed, with respect to the local temperature rise, it suffices to modify the values of the most sensitive physical parameters which define the saturation current, the carrier transit time, etc., in the elementary model. The temperature-dependent GaAs physical parameters are given as $[11,12]$

$$
E_{g}(x, T)=E_{g}(x, 300 \mathrm{~K})-4 \times 10^{-4}(1+0.6 x)(T-300)
$$

where $x$ is the $\mathrm{Al}$ mole fraction, the bandgap $E_{g}$ is in $\mathrm{eV}$ [13].

$$
\begin{aligned}
& \mu_{n}(T)=\mu_{n}(300 \mathrm{~K})\left(\frac{300}{T}\right)^{2.3} \\
& \mu_{p}(T)=\mu_{p}(300 \mathrm{~K})[1-0.0014(T-300)]
\end{aligned}
$$

where $\mu_{n}, \mu_{p}$ are electron and hole mobilities, respectively. 
The saturated electron velocity in $\mathrm{cm} / \mathrm{sec}$ is

$$
V_{s}(T)=10^{7}(1.28-0.0015 T)
$$

The electron and hole diffusion coefficients in $\mathrm{cm}^{2} / \mathrm{sec}$ are

$$
\begin{aligned}
& D_{n}(T)=V_{t}\left[\frac{7200}{\left(1+5.5 \times 10^{-17} N_{B}\right)^{0.233}}\right]\left(\frac{300}{T}\right)^{2.3} \\
& D_{p}(T)=V_{t}\left[\frac{380}{\left(1+3.2 \times 10^{-17} N_{E}\right)^{0.266}}\right]\left(\frac{300}{T}\right)^{2.7}
\end{aligned}
$$

Throughout the analysis, we employed the following assumptions in determining the model with heating effect.

(1) Boltzman statistics are assumed

(2) Two or three-dimensional effects are omitted

(3) Assume the temperature in the intrinsic HBT, which is much higher than room temperature, is spatially independent

(4) The heat generated in the intrinsic HBT is dissipated primarily through the semi-insulated (SI) substrate as shown in Figure 4.

Then the heat $P_{s}(W)$ generated in the HBT [14] is

$$
P_{s}=J_{C} V_{\mathrm{CE}} A_{E}
$$

where $A_{E}$ is the emitter area and $V_{\mathrm{CE}}, J_{C}$ are the applied collector-base voltage and current density, respectively. They are both calculated by the thermionic diffusion model. Thus, $P_{s}$ is related to the thermal resistance $\left(R_{\text {tho }}\right)$ of the substrate as

$$
T-T_{0}=P_{s} R_{\mathrm{th}}
$$

where $T_{0}=300 \mathrm{~K}$ is the ambient temperature. Assume the thermal conductivity $K_{\text {so }}$ is proportional to $\left(T / T_{0}\right)^{-1.22}$ and with kichhoff transformation 


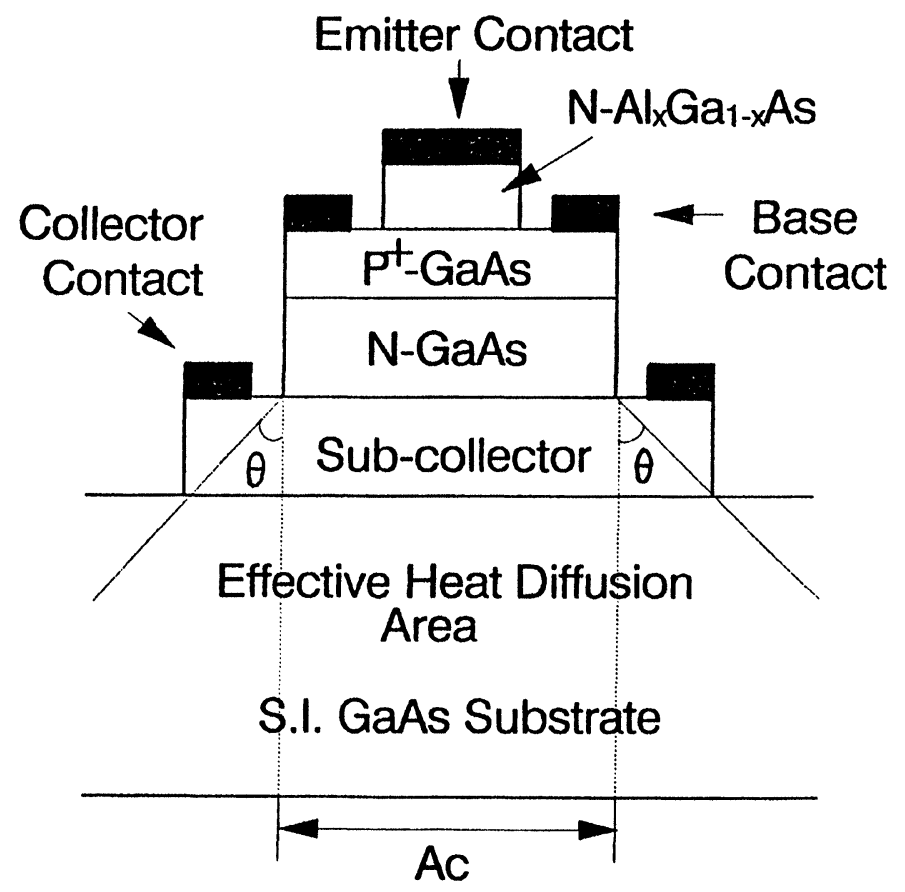

FIGURE 4 Schematic illustration of HBT for the effective area through which the heat is dissipated.

[15], we get

$$
\begin{aligned}
R_{\mathrm{tho}} & =\left(\eta-T_{0}\right) / P_{s} \\
\eta & =\left[1 / T_{0}^{(b-1)}-(b-1) R_{\mathrm{tho}} P_{s} / T_{0}^{b}\right]^{1 / 1-b}
\end{aligned}
$$

and $R_{\text {tho }}$ is the thermal resistance for the case that the thermal conductivity in the substrate is temperature independent. Then,

$$
\begin{aligned}
R_{\text {tho }} & =1 / K_{\text {so }} \int \mathrm{d} x / A_{\text {eff }}(x) \\
A_{\text {eff }}(x) & =A_{c}+2 Z x \tan (\theta) x
\end{aligned}
$$

where $K_{\text {so }}=0.47 \mathrm{~W} / \mathrm{K} \mathrm{cm}$ at $300 \mathrm{~K}$ and $Z, X_{s}$ is the HBT width, the thickness of the SI substrate, respectively. $\theta=45^{\circ}$ is used in our calculation 
[16]. When several iterations are done, the junction temperature and the collector current density $J_{C}$ are obtained. The common-emitter current gain, cut-off frequency and maximum oscillation frequency are also calculated and modified when taking the thermal effect into account.

\section{RESULTS AND DISCUSSION}

The parameters used in the calculations, if not specified, are according to the values in Table 2 . Here, the band parameters of the widebandgap $\mathrm{Al}_{x} \mathrm{Ga}_{1-x} \mathrm{As}$ emitter, such as energy bandgap, dielectric constant, density of state in the conduction and valence bands and intrinsic carrier concentration, etc. are calculated for different $\mathrm{Al}$ mole fractions. The calculated rising temperature is shown in Figure 5 for various applied voltage $V_{\mathrm{BE}}$. As expected, the temperature increases as collector current density is increased beyond $10^{4} \mathrm{~A} / \mathrm{cm}^{2}$ and reach 500 , $600,700 \mathrm{~K}$ at maximum current for $V_{\text {ce }}=4,5$ and $6 \mathrm{~V}$, respectively. It is clearly shown that the device dissipated power in Eq. (31) is proportional to the product of $V_{\mathrm{CE}}$ and collector current density. The junction temperature which increases drastically as high as $500 \mathrm{~K}$, because of a positive feedback between temperature and locally increased current, will cause self-destruction of the transistor. It is well known as "thermal runaway". Therefore, the AlGaAs/GaAs power HBT or other microwave devices, which generate significant heat, will need special process technique (back-side process) to dissipate the generated heat during operation. The back-side process includes wafer thinning, via hole formation, plated heat formatting and dicing into individual chips. The finished devices are usually mounted with the

TABLE II Parameters Used in the Calculation of $f_{\max }$.

\begin{tabular}{ll}
\hline$R_{\mathrm{bm}}$ & $1 \mathrm{ohm}$ \\
$L_{e}$ & $10 \mu \mathrm{m}$ \\
$X_{e}$ & $1 \mu \mathrm{m}, 2 \mu \mathrm{m}, 3 \mu \mathrm{m}$ \\
$W_{\text {ext }}$ & $0.1 \mu \mathrm{m}, 0.2 \mu \mathrm{m}, 0.3 \mu \mathrm{m}$ \\
$X_{b}$ & $3 \mu \mathrm{m}, 4 \mu \mathrm{m}, 5 \mu \mathrm{m}$ \\
$V_{\mathrm{s}}$ & $110^{7} \mathrm{~cm} / \mathrm{sec}$ \\
\hline
\end{tabular}




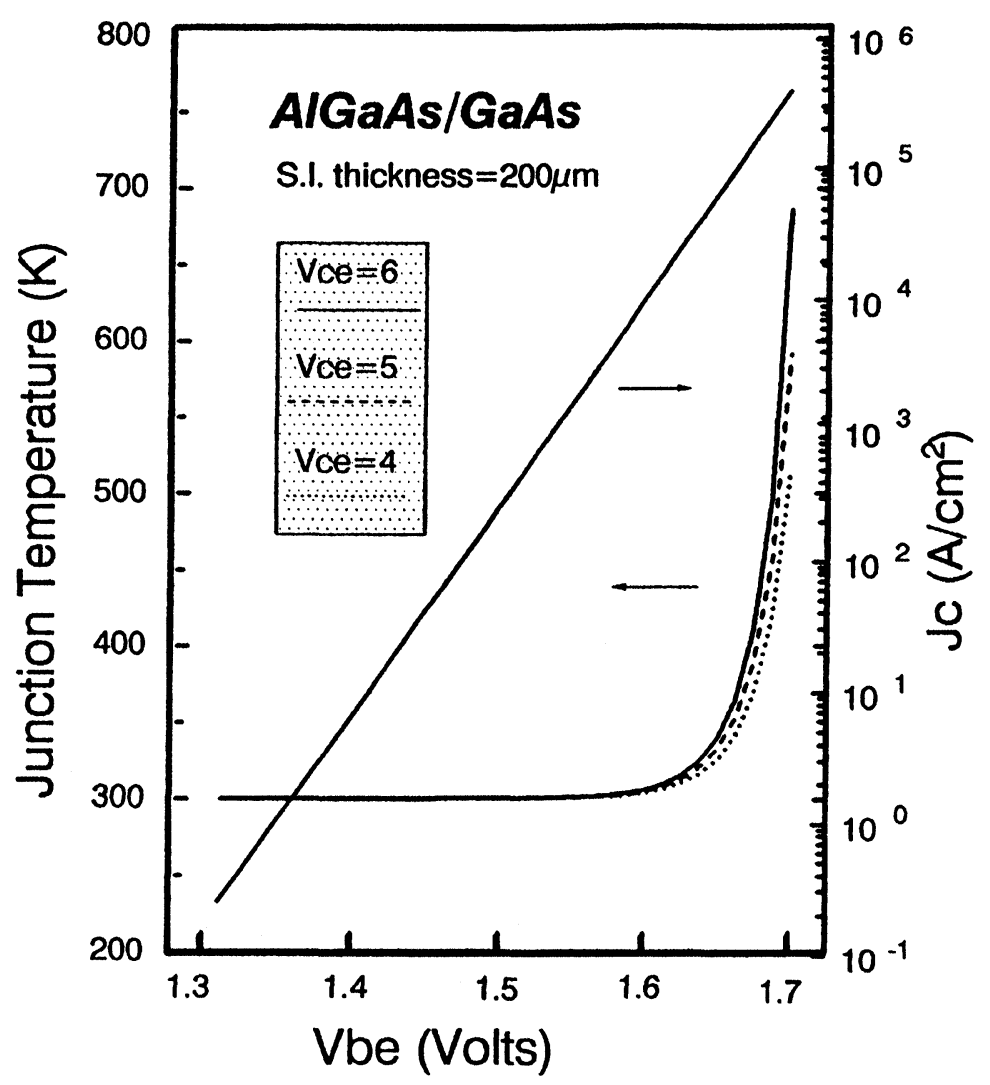

FIGURE 5 Calculated junction temperature and collector current as a function of $V_{\mathrm{BE}}$ where the SI substrate thickness is $200 \mu \mathrm{m}$.

front side upward and the bottom soldered or epoxied to another material which serves a heat sink. Hence, most of the heat generated in the front of the slice must be conducted through the GaAs SI substrate and into the heat sink. Unfortunately, GaAs is a poor thermal conductor, this requires that GaAs SI substrate to be thinned down from its original thickness to a significantly low value $(150$ to $50 \mu \mathrm{m})$. Such thinning is absolutely necessary for power HBT and medium to high power Monolithic Microwave Integrated Circuits (MMICs); these devices require low thermal impedance [17]. Figure 6 shows that the 


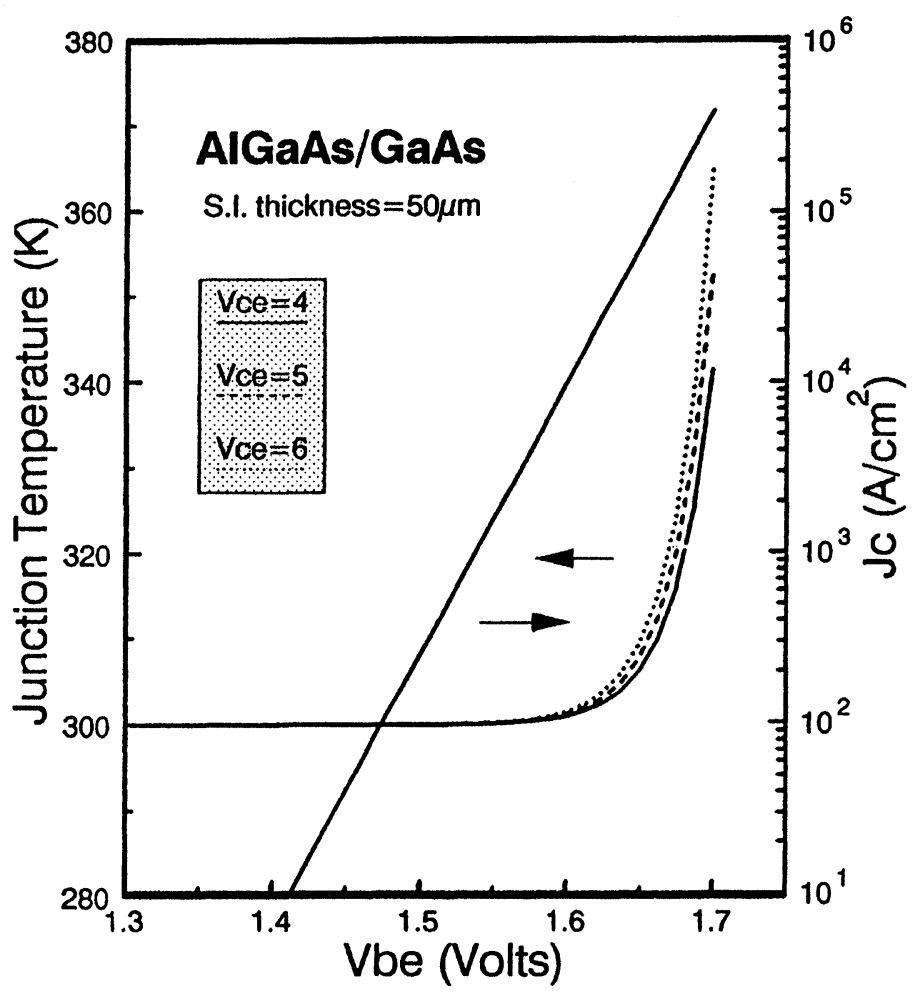

FIGURE 6 Calculated junction temperature and collector current as a function of $V_{\mathrm{BE}}$ where the SI substrate thickness is $50 \mu \mathrm{m}$.

junction temperature reaches only $340,350,365 \mathrm{~K}$ as compared to those in Figure 5, when the SI substrate thickness is thinned down from $200 \mu \mathrm{m}$ to $50 \mu \mathrm{m}$, as discussed above. Figure 7 shows the calculated junction temperature as a function of $V_{\text {ce }}$ where $I_{b}=0.5 \mathrm{~mA} / \mathrm{step}$ and SI substrate thickness is thinned down to $50 \mu \mathrm{m}$. Calculated $I V$ characteristics as shown in Figure 8 exhibit a negative slope when the base current density is high (or $V_{\mathrm{CE}}$ is large), is a phenomenon commonly observed in AlGaAs/GaAs HBT DC measurements. The negative slope in Figure 8 is larger than that in Figure 9 due to the thin down process. Also, as shown in Figure 10, the current gain decreases at moderate to high values of collector current. If the device is assumed 


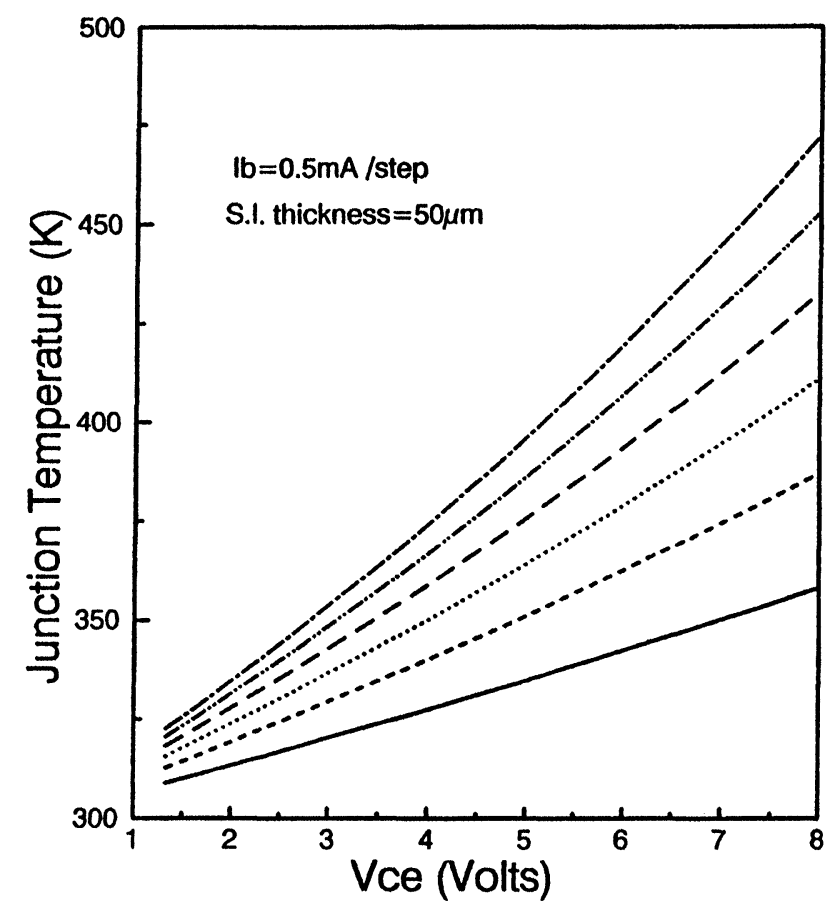

FIGURE 7 Calculated junction temperature as a function of $V_{\text {ce }}$ where $I_{b}=0.5 \mathrm{~mA} / \mathrm{step}$ and the SI substrate thickness is $50 \mu \mathrm{m}$.

to be at ambient temperature $(300 \mathrm{~K})$ throughout its volume, solid line indicate that current gain $\beta$ rises monotonically with collector current. Thus, we conclude that the drastic decreases in $\beta$ at high current is resulted from the temperature effect. But it is difficult to isolate and identify the precise importance of the various factors which could contribute to the reduction in gain because they are interlinked in a complex fashion by electrothermal coupling. For example, electrical effects due to the base resistance tend to produce current crowding at the edges of the emitter, while the thermal effects tend to concentrate the current at the center of the emitter. Therefore, the combination of these two phenomena could conspire to produce a nearly uniform current distribution. However, one factor that can be expected through the electron diffusivity in the base, and the negative tem- 


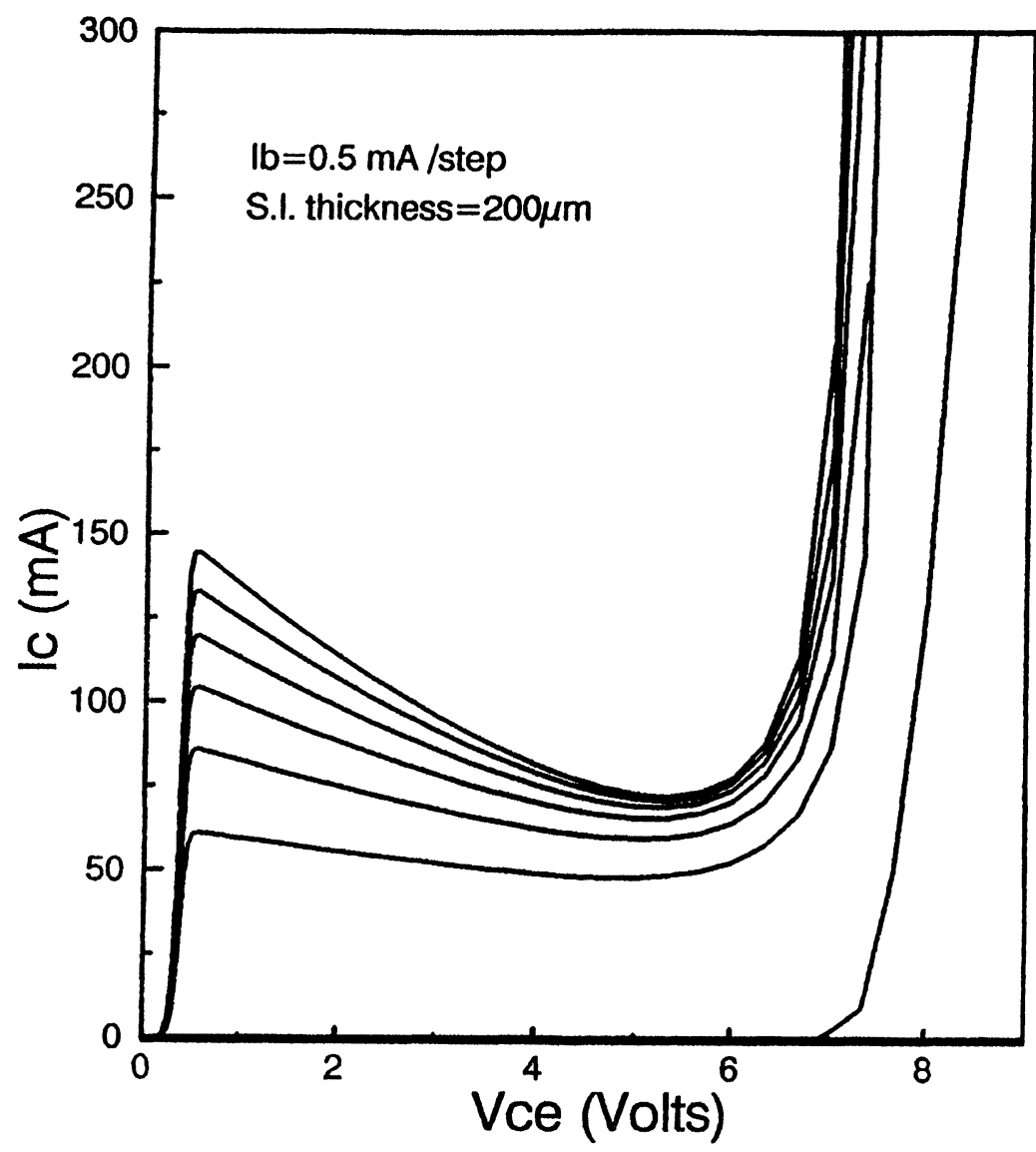

FIGURE $8 I V$ characteristics for the SI substrate with a thickness of $200 \mu \mathrm{m}$.

perature dependence of the mobility is brought into the model. Using Eq. (26) and the definition of the base transport factor $\delta$ given as [18]

$$
\delta(T)=\frac{\tau_{\mathrm{nB}}}{\tau_{B}(T)}=2 \frac{\tau_{\mathrm{nB}} D_{\mathrm{nB}}(T)}{W_{B}^{2}}=\delta(300 \mathrm{~K})\left(\frac{300}{T}\right)^{1.3}
$$

we have clearly known the temperature dependence of $\mu_{\mathrm{nB}}$ does not only account for the variation of $\beta$. As the emitter injection efficiency is a con- 


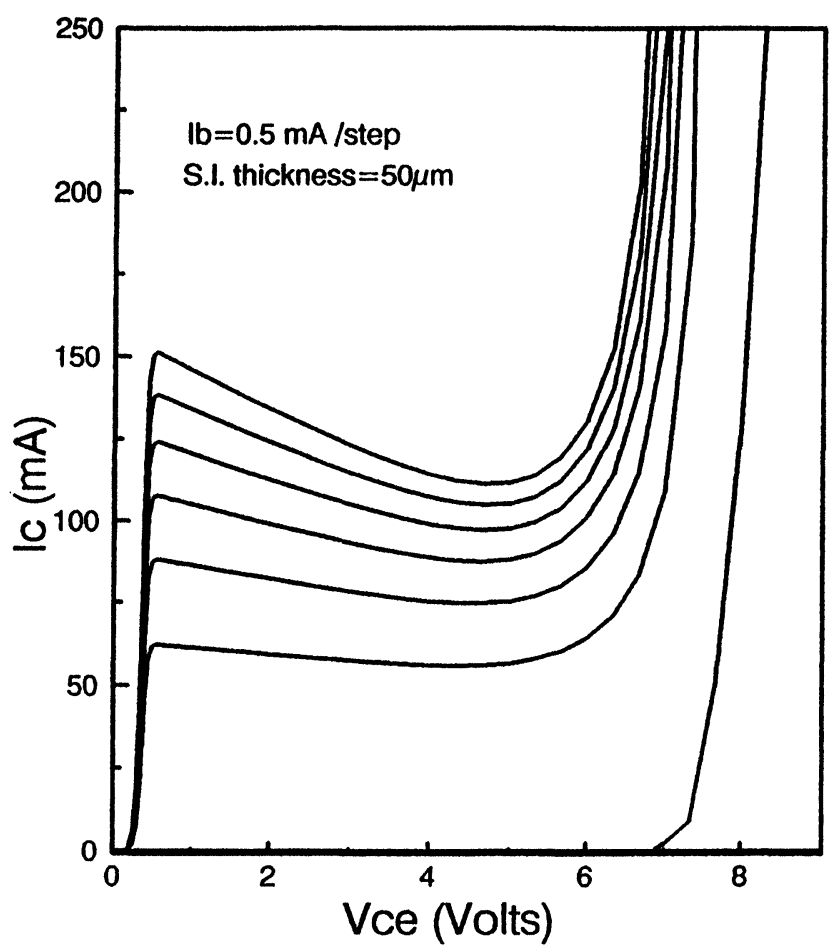

FIGURE $9 I V$ characteristics for the SI substrate with a thickness of $50 \mu \mathrm{m}$.

stant, it follows that recombination in the emitter-base space charge region is significant. The combination of $V_{\mathrm{BE}}$ falling toward the center of the emitter, due to electrical series resistance in the base, the increase of intrinsic carrier concentration and the negative temperature dependence of the bandgap, makes the increase of recombination in space charge region which cause base current increasing drastically. Therefore, a drastic reduction in $\beta$ will occur, especially when $V_{\mathrm{CE}}$ increases from 4 to $6 \mathrm{~V}$. As discussed above, the $\beta$ will collapse at higher collector current density in the thinned device as shown in Figure 11 , at which the $\beta$ decreases at $J_{C}$ about $1.3 \times 10^{5} \mathrm{~A} / \mathrm{cm}^{2}$, while decreases at $4 \times 10^{4} \mathrm{~A} / \mathrm{cm}^{2}$ shown in Figure 10 . Calculated $f_{T}$ and $f_{\max }$ at different collector-emitter voltage are shown in Figure 12 and Figure 13, respectively. The $f_{T}$ increases from low to moderate collector current density and then decreases at high collector current density. The decrease of $f_{T}$ in low collector current is resulted from a higher 


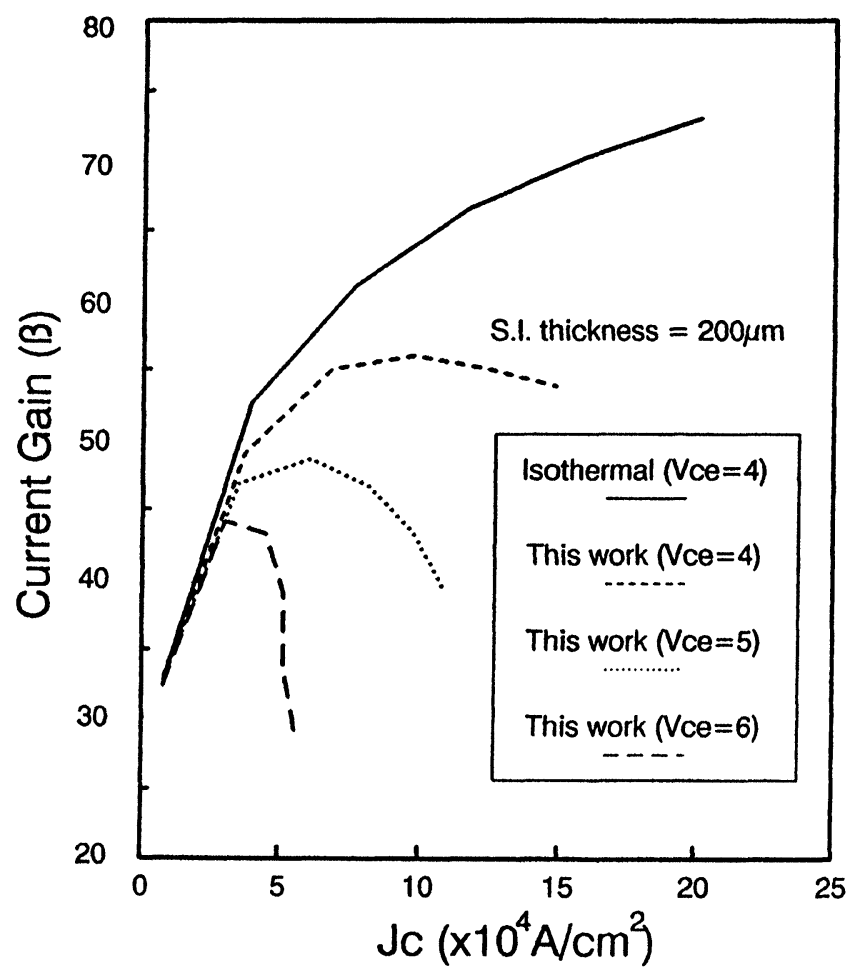

FIGURE 10 Calculated current gain versus collector current density with $V_{\text {ce }}$ voltages as parameters for SI substrate thickness of $200 \mu \mathrm{m}$.

charging time $\tau_{\mathrm{eb}}$ due to a higher emitter diffusion resistance at low collector current. The $f_{T}$ degradation in high current region is due to base widening effect which increase the base transit time and increased emitter junction resistance. It is interesting to find that $f_{T}$ is reduced by the increase of $V_{\text {ce }}$, and $f_{\max }$ actually increases slightly but falls off at a low collector current density when $V_{\text {ce }}$ is increased. These results clearly show that the commonly observed behavior of $\beta, f_{T}$ and $f_{\max }$ at high $J_{C}$ can be accurately predicted by the present model. The rapid fall-off properties, which degrades the HBT performance, are caused mainly by the higher temperature in the HBT associated with the high $J_{C}$ and large $V_{\text {ce }}$. The high temperature also results in the kirk effect at a low $J_{C}$. 


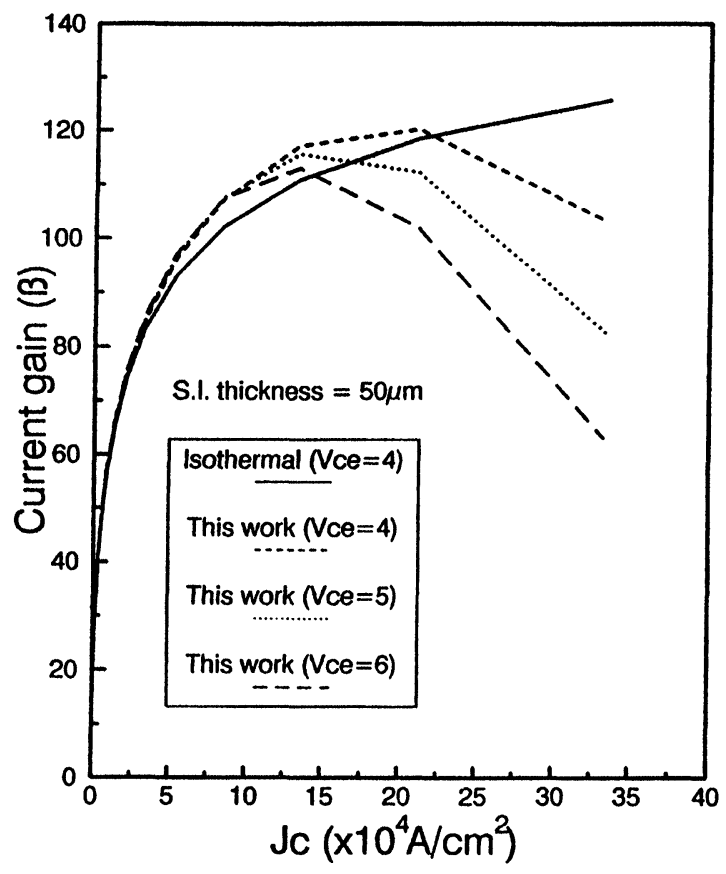

FIGURE 11 Calculated current gain versus collector current density with $V_{\text {ce }}$ voltages as parameters for SI substrate thickness of $50 \mu \mathrm{m}$.

\section{CONCLUSIONS}

In this paper, we pay attention to predicting the HBT behavior and physical trends and also have developed a physics-based analytical HBT thermal model associated with the thermal effects. When comparing the present model with iso-thermal model, it is found that the thermal effect is the main mechanism contributing to the commonly observed fall-off behavior in power HBTs operated at high current region. From the iso-thermal model, we can optimize the device parameters and achieve better current-dependent $\beta, f_{T}$ and $f_{\max }$. To obtain higher $f_{T}$ and $f_{\max }$, a smaller value of collector thickness should be used to shorten collector charging time $\tau_{\mathrm{bc}}$. Higher collector doping concentration may be required to avoid the base widening effect. However, higher collector doping concentration results in larger basecollector capacitance which cause large base-collector depletion 


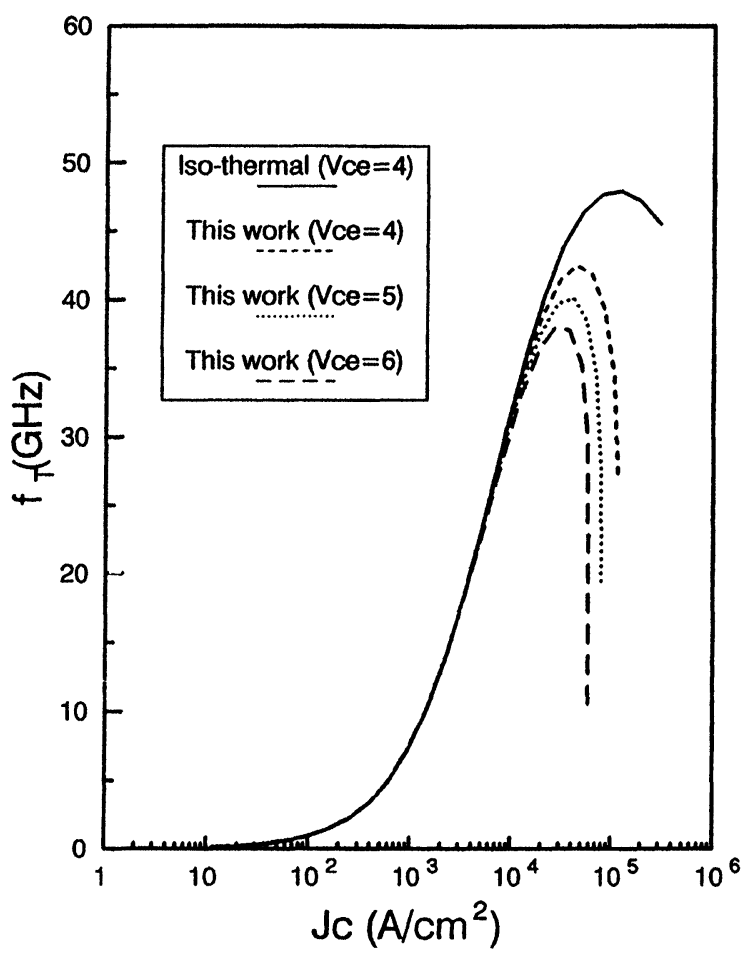

FIGURE 12 Calculated $f_{T}$ versus $J_{C}$ at different $V_{\text {ce }}$ voltages in the thermal model.

transit time $\tau_{\mathrm{bc}}$ and results in smaller breakdown voltage $\left(\mathrm{BV}_{\mathrm{cbo}}\right)$. Therefore, a trade-off between breakdown and speed should have to be made. In addition, we supply an estimated tool of the junction temperature effects on the electrical characteristics of the semiconductor devices. This will be of particular benefit when modeling devices with unfamiliar package or heat sink configurations. In practical design, some back-side process such as substrate via process and thinning for reduction of material resistance are used and ensured in lower temperature operation. Due to the understanding of the thermal design, a conceptual realization in the thermal properties of HBT will enhance our understanding to implement an improved RF performance. 


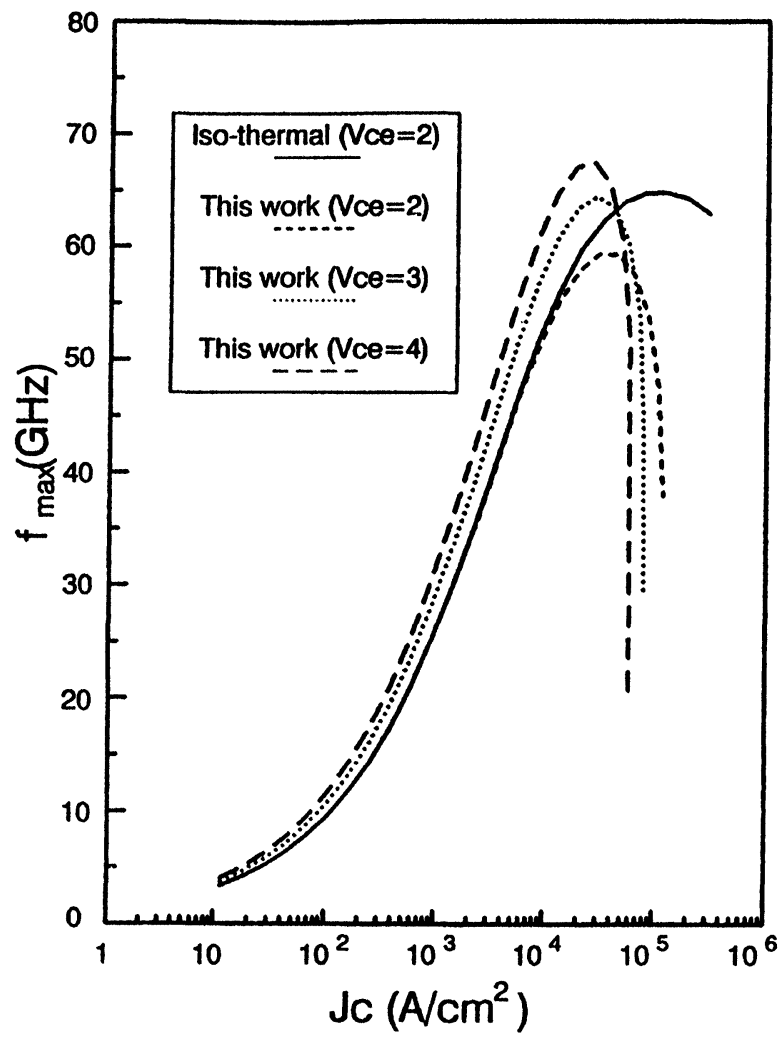

FIGURE 13 Calculated $f_{\max }$ versus $J_{C}$ at different $V_{\text {ce }}$ voltages in the thermal model.

\section{References}

[1] Kroemer, H. (1957). Proc. IEEE, 45, 1535.

[2] Asbeck, P. M., Miller, D. L., Peterson, W. C. and Kirkpatrick, C. G. (1982). IEEE Electron. Dev. Lett., EDL-3, 366.

[3] Asbeck, P. M., Chang, M. F., Higgins, J. A. and Sheng, N. H. (1989). IEEE Trans. Electron. Dev., ED-36, 2032.

[4] Lee, K., Shur, M., Fjeldly, T. A. and Ytterdal, T. (1993). Semiconductor Device Modeling for VLSI. Prentice-Hall Inc.

[5] Gao, G. B., Chyi, J. I., Chen, J. and Morkoc (1990). Solid-State Electron., 33, 389.

[6] Sze, S. M. (1981). Physics of Semiconductor Devices. Wiley.

[7] Liou, J. J. and Shakouri, H. (1992). Solid-State Electron., 35, 15.

[8] Cooke, H. F. (1971). Proc. IEEE, 59, 1163.

[9] Tan, S. S. and Milnes, A. G. (1983). IEEE Trans. Electron. Dev., ED-30, 1289.

[10] Sunderland, D. A. and Dapkus, P. L. (1987). IEEE Trans. Electron. Dev., ED-34, 367. 
[11] Barker, D. W. (1989). PhD Thesis. Cornell University.

[12] Marty, A., Camps, T., Tasselli, J., Pulfrey, D. L. and Bailbe, J. P. (1993). IEEE Trans. Electron. Dev., ED-40, 1202.

[13] Shur, M. (1987). GaAs Devices and Circuits. Plenum.

[14] Liou, J. J., Liou, L. L., Huang, C. I. and Bayraktaroglu, B. (1993). IEEE Trans. Electron. Dev., ED-15, 1570.

[15] Joyce, W. B. (1975). Solid-State Electron., 18, 321.

[16] Casey, H. C. and Panish, M. B. (1978). Heterostructure Lasers. Academic Press.

[17] Williams, R. E. (1984). Gallium Arsenide Processing Techniques. Artech House Inc.

[18] Bailbe, J. P., Marty, A., Rey, G., Tasselli, J. and Bouyahyaoui, A. (1985). SolidState Electron., 28, 627. 

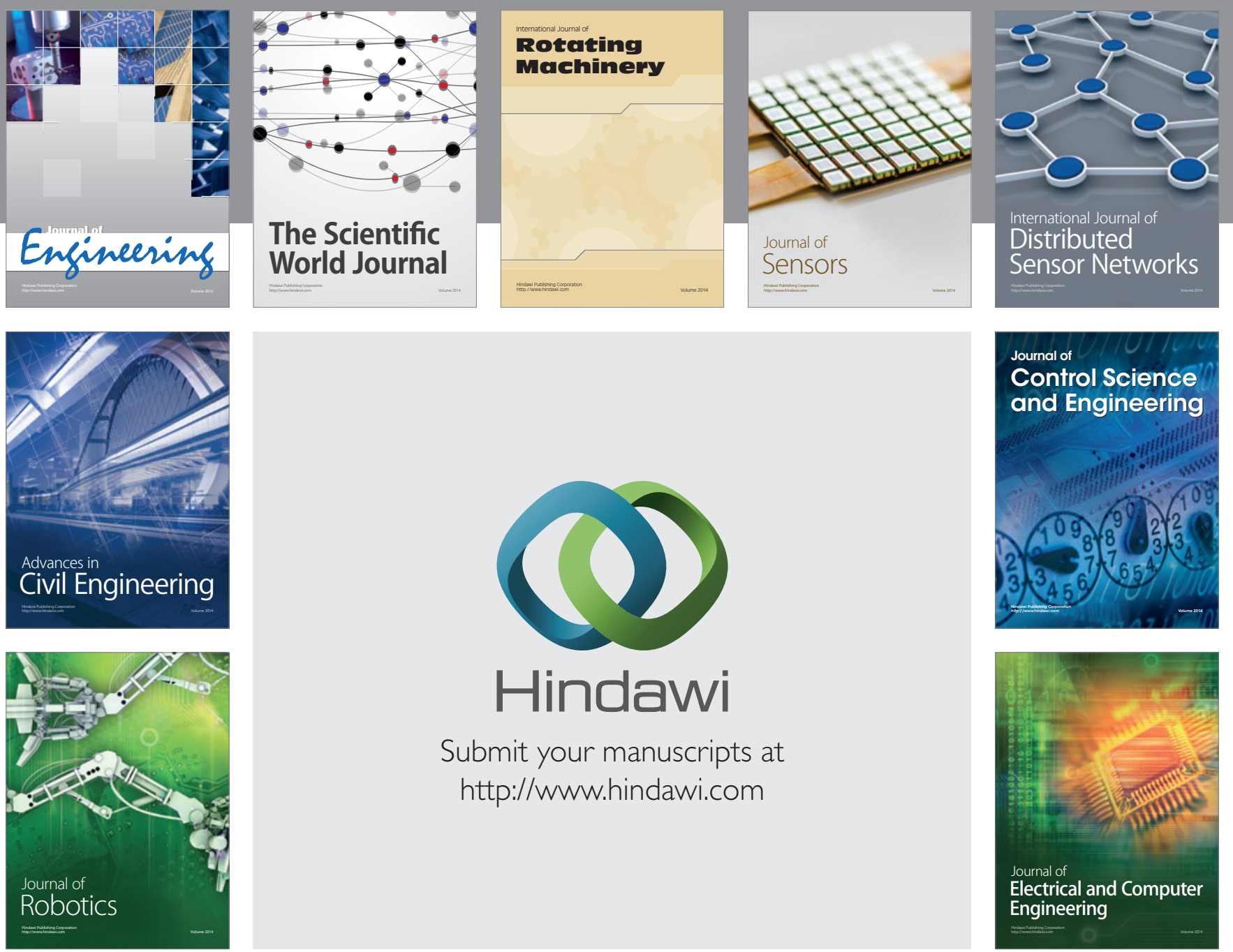

Submit your manuscripts at

http://www.hindawi.com
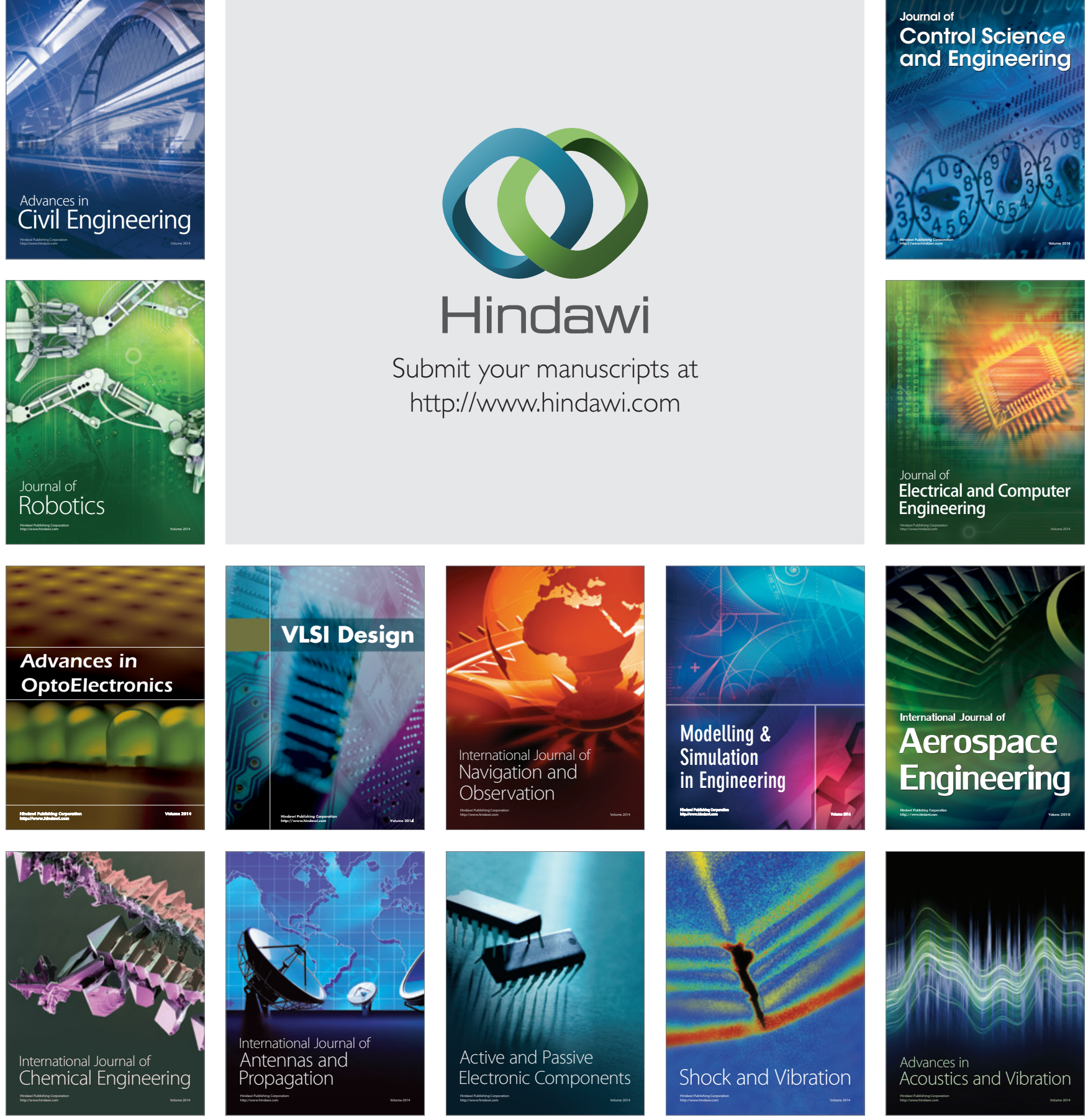